\title{
BMJ Open Mental well-being of patients from ethnic minority groups during critical care: a qualitative ethnographic study
}

\author{
Rose Lima Van Keer, ${ }^{1}$ Reginald Deschepper, ${ }^{1}$ Luc Huyghens, ${ }^{2}$ Johan Bilsen ${ }^{1}$
}

To cite: Van Keer RL, Deschepper R, Huyghens L, et al. Mental well-being of patients from ethnic minority groups during critical care: a qualitative ethnographic study. BMJ Open 2017;7:e014075. doi:10.1136/ bmjopen-2016-014075

- Prepublication history and additional material for this paper are available online. To view please visit the journal (http:// dx.doi.org/10.1136/bmjopen2016-014075).

Received 30 August 2016 Revised 3 August 2017 Accepted 4 August 2017

CrossMark

${ }^{1}$ Mental Health and Wellbeing Research Group (MENT), Department of Public Health, Faculty of Medicine and Pharmacy, Vrije Universiteit Brussel, Brussels, Belgium ${ }^{2}$ Critical care Department/ Service of Intensive Care Medicine, Vrije Universiteit Brussel, Universitair Ziekenhuis Brussel, Brussels, Belgium

Correspondence to Rose Lima Van Keer; rvkeer@vub.ac.be

\begin{abstract}
Objectives To investigate the state of the mental wellbeing of patients from ethnic minority groups and possible related risk factors for the development of mental health problems among these patients during critical medical situations in hospital.

Design Qualitative ethnographic design.

Setting Oneintensive care unit (ICU) of a multiethnic urban hospital in Belgium.
\end{abstract}

Participants 84 ICU staff members, 10 patients from ethnic-minority groups and their visiting family members. Results Patients had several human basic needs for which they could not sufficiently turn to anybody, neither to their healthcare professionals, nor to their relatives nor to other patients. These needs included the need for social contact, the need to increase comfort and alleviate pain, the need to express desperation and participate in end-of-life decision making. Three interrelated risk factors for the development of mental health problems among the patients included were identified: First, healthcare professionals' mainly biomedical care approach (eg, focus on curing the patient, limited psychosocial support), second, the ICU context (eg, time pressure, uncertainty, regulatory frameworks) and third, patients' different ethnocultural background (eg, religious and phenotypical differences)

Conclusions The mental state of patients from ethnic minority groups during critical care is characterised by extreme emotional loneliness. It is important that staff should identify and meet patients' unique basic needs in good time with regard to their mental well-being, taking into account important threats related to their own mainly biomedical approach to care, the ICU's structural context as well as the patients' different ethnocultural background.

\section{INTRODUCTION}

Having a good mental health/well-being means more than not having a mental disorder. The WHO defines mental wellbeing as ' a state of well-being in which an individual realizes his or her own abilities, can cope with the normal stresses of life, can work productively and is able to make a contribution to his or her community'. It is perceived as crucial to our capacity as people to think, communicate with others, earn money and enjoy life. Risk factors include individual factors on,

\section{Strengths and limitations of this study}

As far as we know, this is the first study where the mental well-being of patients from ethnic minority groups is profoundly investigated by means of an ethnographic research design.

- By studying the mental well-being of these patients as is 'genuinely expressed', from multiple perspectives and in a contextual manner, through ethnographic fieldwork in an intensive care unit (ICU) of a multiethnic urban hospital in Belgium, we have tried to develop a nuanced, non-stereotypical and rich insight into such patients' mental wellbeing.

- One limitation of this research could be the fact that the fieldwork was done in only one ICU. Therefore, transferability to other situations must be done with caution. However, by spending a lot of time in a variety of situations (with 10 patients and their families and all their healthcare professionals), it was possible to gain a rich insight into our sensitive research topic.

for example, the socioeconomical level (eg, being poor, having a low educational level), cultural level (eg, belonging to an ethnic minority group) and behavioural level (eg, having an unhealthy life style, having little sleep), contextual/structural factors (eg, facing adverse work conditions, discrimination) and biological/genetical factors (eg, being physically ill). ${ }^{12}$ It is then no surprise that during critical care patients' mental wellbeing comes under threat and especially when other risk factors are involved, for example, when patients have a different ethnocultural background. ${ }^{34}$

Hallucinations, fear and depression frequently occur among patients admitted to the intensive care unit (ICU) ${ }^{5-8}$ Several risk factors are identified, including invasive treatments, separation from family, physical pain, immobility, dependency, lack of control, lack of privacy and poor communication. ${ }^{45-11}$ Although disturbances in critically ill patients' mental health negatively 
affect their whole care process, healthcare professionals working in a critical care setting lack adequate strategies to improve patients' mental health. They are often not aware of patients' mental health problems as they mainly focus on the technological care aspects and lack training in mental care. Many critical care nurses, for example, do not have enough insight in the elements that might affect their patients' psychological state. ${ }^{9} 12$ Furthermore in society at large, mental health problems remain a sensitive issue as such problems are often difficultly acknowledged and talked about.

Additionally, healthcare professionals have to communicate increasingly with patients from ethnic minority groups, that is, persons of a different origin who share certain cultural characteristics to some extent, ${ }^{13}$ as a result of societies' increased ethnocultural diversity. In Belgium, healthcare for migrants is basically organised in the same manner as for people from the ethnic majority group. However, it is known that during the care for migrants, problems regularly arise which are situated on mainly two levels, namely first health differences (ethnic minorities have less chance on a healthy life than people from the ethnic majority group) and second problems regarding the accessibility and use of healthcare services (ethnic minorities have lower access to healthcare services and receive less quality care than members of the ethnic majority group). Problems are often very complex and related to different factors, such as linguistic and cultural differences. ${ }^{14}$ We might assume that critically ill patients from ethnic minority groups are at an even higher risk of mental health problems and that ethnocultural differences render mental health problems more complex and multifaceted. Inattention by healthcare professionals to specific ethnocultural habits (eg, gender segregation), discrimination, unfamiliarity with the western healthcare system and different foodways can contribute to traumatic experiences for ethnic minorities. ${ }^{15-18}$ Furthermore, language differences and ethnocultural norms prescribing acceptance of physical suffering can lead to less adequate communication and pain relief, ${ }^{19}{ }^{20}$ which can endanger such patients' psychological state. ${ }^{71521}$ Yet, although we increasingly live in a multiethnic society, research about the mental well-being of patients from ethnic minority groups during critical care is rather scarce and there are very few in-depth studies which try to understand this topic in its specific context and from different angles.

In this study, we therefore aim to investigate 'the state of the mental well-being of patients from ethnic minority groups and possible related risk factors for the development of mental health problems among these patients in a multiethnic ICU'. In-depth understanding of occurrences of mental health problems among patients from ethnic minority groups can contribute to the development of recommendations to prevent such problems for these patients.

\section{METHODS}

Patients' mental well-being in a multiethnic critical care setting is a sensitive, complex and novel topic of research. Therefore, an ethnographic research design has been used, which gave the researcher the opportunity to immerse herself into her study field and study the research topic for a long period on the workfloor itself. By getting a feel of the lifeworld of the ICU, observing and interacting with different parties, the researcher was able to grasp the research topic in all its different facets and from different angles. ${ }^{22-24}$

\section{Participants and setting}

Ethnographic fieldwork was done in one ICU of a multiethnic urban hospital in Belgium over 6 months (January 2014-June 2014). Forty per cent of the ICU patients are estimated to belong to an ethnic minority group. Staff's, patients' and relatives' behaviour, interactions and experiences were studied for 360 hours. The selected patients and the family members who accompanied them, as well as their healthcare professionals, were followed for the whole critical period. No relationship was established with the research participants prior to the beginning of the study. Patients and their family members were purposefully selected and approached face-to-face. They were only eligible for inclusion in the study if the patient or at least one of his/her legal parents was born abroad, if at least one of the family members (patient/his or her relatives) was able to speak Dutch, French or English and if the patient was at least 18 years old. In total, we selected 10 patients and their visiting family members, who were originally from Morocco, Algeria, Turkey, Congo and Portugal. No patients and relatives refused to participate. The patients were between 40 and 82 years old and consisted of six males and four females. They were admitted for complicated pneumonia (3), abdominal problems (1), heart problems (2), brain haemorrhage (2), cancer (1) and a severe accident (1). All patients were sedated for some time and as a result were unable to communicate or only had limited ability to communicate, depending on the level of sedation. The critical care team consisted of 80 nurses and 12 doctors, who were almost all white Caucasians from the dominant ethnic group. Eight staff members refused to participate in the study. Of course also other people were present during the ethnographic fieldwork, for example, doctors who mostly work in other wards. Research participants were aware of the researcher's reason for doing the research (improving intercultural communication in the ICU). (For further information about patients, see online 'supplementary file Patients characteristics').

\section{Data collection}

Data were collected through triangulation of several data collection strategies, namely negotiated interactive observation, ${ }^{22}$ in-depth interviews with healthcare professionals $^{23}$ and the reading of patients' medical records. In an ICU setting, typified among other things by time 
pressure and highly specialised lifesaving care tasks, it is very difficult for the researcher to fully participate in the core activities of social life on the ward. Therefore, 'negotiated interactive observation' was chosen, meaning that before starting the observations, the researcher always implicitly or explicitly asked permission for it to the research participants. ${ }^{22}$ This technique enabled the researcher to gain the trust of the research participants easily. Negotiated interactive observation gave the researcher the opportunity to have 480 informal conversations with healthcare professionals, family members and patients, attend 144 staff meetings and witness 375 interactions between healthcare professionals, relatives and patients during visiting hours.

When the researcher was in the ICU, she made notes in a logbook. After the researcher had left the ICU, she transformed these notes into comprehensive descriptive field notes containing observations of participants' discourse, behaviour and interaction, informal conversations with them as well as researcher's reflections on her behaviour and feelings in the field. ${ }^{23}$ Formal in-depth interviews were held with nine healthcare professionals in two meeting rooms in the hospital. The interview questions were based on an interview guide, which was discussed among experts before the actual data collection started and pilot tested among a limited number of persons (see online supplementary file 'Topic list interviews'). The interviews lasted between $50 \mathrm{~min}$ and $1 \mathrm{~h} 30 \mathrm{~min}$ and were audiorecorded. Interview transcripts were not returned to the research participants for comments or corrections. All data were collected by the first author (RLVK), a trained ethnographer and sociologist (MSc) who was doing academic scientific research at university at the time of the study. She is extensively trained in qualitative research.

\section{Data analysis}

The analysis started with a 'thick description, 25 of participants' discourse, behaviour and interaction and was followed by a grounded theory analysis. ${ }^{26}$ In-depth interviews were transcribed, and data were conceptualised by means of a three-step coding process, supported by NVIVO 8 (QSR International, 2008). This process resulted in the creation of a conceptual model, consisting of different themes and subthemes. First, an open coding phase was performed, involving the reading and rereading of the data. This resulted in the formation of different codes, for instance 'physical contact', 'proximity' and 'fighting'. To find similarities and differences between these codes, new codes were constantly compared with already existing codes. Second, axial coding took place. This led to the formation of groupings of similar codes, that is, categories, for example, 'social contact' and 'saving patient'. Relationships between the categories were also established, for instance, 'basic needs' and 'care strategies'. Third, selective coding was performed to determine the core category ('emotional loneliness') around which the related categories are clustered. ${ }^{26} 27$
Data collection and analysis were stopped when the point of saturation was reached. ${ }^{26}{ }^{28}$ Reliability was strengthened by the first author (RLVK) doing the data analysis and two coauthors (RD and JB) doing a peer-revision of the analysis. The process of data collection and data analysis was also regularly discussed by members of the multidisciplinary academic research group in which these authors participate, consisting of a health scientist, a psychiatric nurse, two anthropologists and one sociologist. To improve the reliability and accuracy of the study, the results were also read by an intensive care specialist who is part of the intensive care team at the hospital in which the researcher did her fieldwork. Furthermore, the study results were presented to and discussed with the nurses who had participated in this study during a conference.

\section{Ethics}

The research protocol (reference 2013/371) was approved by the university ethics committee of the Vrije Universiteit Brussel. The privacy of the research participants and confidentiality of the data were respected, for example, by using pseudonyms. Written consent to participation in the study was sought from healthcare professionals, family members and patients who were still able to communicate. If the patient lacked the capacity to give consent, consent was sought from his/her legal representative.

\section{RESULTS}

The patients included were admitted for complicated pneumonia (3), abdominal problems (1), heart problems (2), brain haemorrhage (2), cancer (1) and trauma (1). Mental health problems came overtly to the fore among patients. Patients had several basic needs for which they could not sufficiently turn to anybody, neither to their healthcare professionals, nor to their relatives nor to other patients. These needs comprised the need for social contact, non-medical information exchange, the need to increase comfort and alleviate pain, the need to express desperation and to participate in end-of-life decision making'.

\section{Need for social contact}

Patients longed for social contact with relatives, healthcare professionals and other patients verbally and non-verbally. This need became even more significant when patients were unable to communicate verbally as a result of their medical state and/or language differences. More specifically, patients longed for proximity of others, physical contact and chatting.

Patients wanted their relatives and friends to be close to them, felt the need to touch and/or kiss them and talk or write to them. Therefore, patients wanted their loved ones to stay longer than accepted during visiting time, to come more often or to take them back home (see table 1a in online supplementary file 'Quotes'). Some 
patients also wanted to phone home to request visits from relatives (see table $1 \mathrm{~b}$ in online supplementary file 'Quotes'). Furthermore, patients wanted healthcare professionals to communicate more often with them (see table 1c in online supplementary file 'Quotes'). However, the rules concerning visits, the infrastructure/ accommodation (eg, no telephone) and healthcare professionals' focus on the patients' disease made it difficult for staff to fully satisfy patients' need for social contact. Moreover, pressure of work and time made it tough to communicate with patients. Furthermore, language differences and misconceptions of healthcare professionals towards patients' ability to communicate in the language of the host country, sometimes based on patients' different skin colour, endangered the meeting of patients' social needs (see table $1 \mathrm{~d}$ in online supplementary file 'Quotes'). Some patients also felt the urge to connect with other patients. This became indirectly apparent when patients stared at other beds and/or asked questions about other patients' conditions. Nonetheless, infrastructural constraints (eg, remote beds) and language differences made communication between patients impossible (see table 1e in online supplementary file 'Quotes').

\section{Need for non-medical information exchange with healthcare professionals}

The information exchange between doctors and patients was primarily of a medical nature. When patients were conscious, doctors explained to patients their medical situation, which medical actions they had undertaken as well as those they would undertake in the future and which medical decisions had been taken. However, patients felt the need to get medical information regarding their physical state from healthcare professionals and to exchange information with them on matters that were not strictly medical, for example, practical issues, visual aspects (eg, activities going on around them) and their family (see table 2a and $\mathrm{b}$ in online supplementary file 'Quotes'). Furthermore, nurses regularly did not communicate with patients or only communicated with them in a task-related manner (see table 2c in online supplementary file 'Quotes').

Despite healthcare professionals' good intentions, they often perceived it as impossible to communicate with patients about non-medical issues due to their prime task of safeguarding the patients' clinical state, time pressure and their workload (see online table $2 \mathrm{~d}$ in supplementary file 'Quotes'). Also language differences made communication between patients and healthcare professionals about non-medical matters more difficult (see table 2e in online supplementary file 'Quotes'). In addition, communication with relatives about non-medical issues was limited as well. Relatives often focused on their search for exhaustive medical information from doctors, which was reinforced by group pressure within their families, during the restricted visiting hours.

\section{Need to increase comfort and alleviate pain}

Patients wanted to increase their comfort and be free from pain. This need was often expressed through verbal and non-verbal communication. Patients verbally requested acts of care to increase comfort in the language of the host society or in their own mother tongue. They also often indirectly requested comfort-increasing care by expressing their suffering through non-verbal signs, for example, pointing with their heads. However, sometimes these expressions of patients' hardship were not noticed, minimally acknowledged, not apprehended or misunderstood, even neglected, normalised or temporarily medically suppressed by giving tranquillisers, by healthcare professionals. Inadequately meeting patients' need for comfort and pain alleviation was related to healthcare professionals' workload, time pressure, their focus on strictly medical care task and actual/falsely perceived language differences. Consequently, comfort and pain was often addressed based on healthcare professionals' unilateral assessment, sometimes leading to mistrust between themselves and patients and irritation and insecurity occurred on both sides (see table $3 \mathrm{a}$ in online supplementary file 'Quotes').

Patients' non-verbal care requests were sometimes not seen or neglected by healthcare professionals because they were too occupied with medical care tasks. Apprehension by healthcare professionals of patients' verbal messages was sometimes hampered by language differences (see table $3 \mathrm{~b}$ in online supplementary file 'Quotes'). Moreover, when patients' non-verbal expressions of suffering were noticed, communication with patients sometimes unfolded inadequately or no communication occurred. This was sometimes related to healthcare professionals' misconceptions of patients' language proficiency, based on the very quick and minimal moments of interaction they had with patients and relatives and patients' different skin colour. Also, staff's general knowledge of patients' country of origin which they sometimes easily applied to all patients from that country contributed to these misconceptions (see table $3 \mathrm{c}$ in online supplementary file 'Quotes').

On the other hand, some patients who were at moments totally unable to communicate as a result of medical and linguistic barriers were automatically perceived as quiet patients who were comfortable/painless (see table 3d in online supplementary file 'Quotes'). When patients experienced discomfort for a longer time, some of them did not want to ask healthcare professionals for help anymore and wanted to leave the ICU (see table $3 \mathrm{e}$ in online supplementary file 'Quotes').

\section{Need to express desperation}

Among some patients, feelings of desperation were observed at times. Some of them wanted to leave the hospital, others wanted to completely give up treatment (see table 4a in online supplementary file 'Quotes'). Patients felt the need to express and share these feelings with others. However, patients regularly felt obliged to 
suppress their hopelessness during critical care in front of healthcare professionals and relatives, resulting in frustration and sadness.

Healthcare professionals did not stimulate expressions of desperation. They frequently presented patients with their situation in a hopeful manner and tried to motivate them to not give up, leaving little space for patients to express their negative feelings. And even when patients did express their hopelessness, healthcare professionals often did not respond. Moreover, when patients became very overtly anxious/hopeless, tranquillisers/antidepressants were given (see table $4 \mathrm{~b}$ in online supplementary file 'Quotes').

Additionally, family members remained hopeful and consequently also spoke in a hopeful tone to patients (see table 4c in online supplementary file 'Quotes'). Relatives' religious beliefs and high expectations for cure in western hospitals functioned as sources of hope. Furthermore, negative information was hidden for some family members by other relatives so as to not create unrest within their large transnational families, which affected relatives' positive outlook on the patients' situation (see table $4 \mathrm{~d}$ in online supplementary file 'Quotes'). Additionally, families' considerable size led to group pressure among its members to remain hopeful. Moreover, patients themselves presented their situation in a more positive manner towards visiting relatives coming from the home country so as to not worry their relatives there (see table $4 \mathrm{e}$ in online supplementary file 'Quotes').

\section{Need to participate in end-of-life decision making}

Enduring physical and mental suffering triggered a need for some patients to participate in a decision to withdraw therapy. This need was verbally and non-verbally expressed at several points (see table $5 \mathrm{a}$ in online supplementary file 'Quotes').

However, healthcare professionals regularly acknowledged these patients' communication only minimally, neglected it, forgot it or tried to change patients' opinions. Doctors mostly saw themselves as the central decision makers and wanted to continue treatment, when they believed that patients still had a chance to survive within the context of their specific pathology. Patients were seen as lacking the required expertise to make a decision to withdraw therapy. Furthermore, their wishes were perceived as irrational/fluctuating, as they could change after a hopeful conversation with a healthcare professional, after appropriate treatment or after taking antidepressants (see table $5 \mathrm{~b}$ in online supplementary file 'Quotes'). Further, healthcare professionals saw it as their mission to save patients' lives, which was reinforced by their daily contact with many hopeful relatives of the patient who saw God as the ultimate decision maker. Consequently, not being able to save the patient was seen by some healthcare professionals as a personal failure (see table $5 \mathrm{c}$ in online supplementary file 'Quotes').

\section{DISCUSSION}

This ethnographic study investigates the state of the mental well-being of patients from ethnic minority groups and possible related risk factors for the development of mental health problems among these patients in a multiethnic ICU in Belgium. We found that the mental state of critically ill patients from ethnic minority groups is basically characterised by an 'extreme emotional loneliness'. Patients had several human basic needs for which they could not sufficiently turn to anybody, neither to their healthcare professionals, nor to their relatives nor to other patients. It concerned the need for social contact, for non-medical information exchange, the need to increase comfort and alleviate pain, the need to express desperation and participate in end-of-life decision making. Insufficiently meeting patients' basic needs endangered patients' mental well-being as defined by the WHO, for example, in the sense that they could not cope adequately with stress and did not feel to contribute to their family/community anymore. Three inter-related risk factors for the development of mental health problems among the included patients were identified: first, healthcare professionals' mainly biomedical approach to care, second, the ICU context and third, the patients' different ethnocultural background.

The mental well-being of patients from ethnic minority groups in a critical care setting is an under-researched topic. Although a body of research has recently begun to grow that focuses on the lifeworld of patients in a critical care context (see eg, ${ }^{4912}$ ) still very few of these studies focus on specific vulnerable patient groups, for example, patients from ethnic minority groups and mental health issues. Furthermore, some researchers who do focus on patients who are critically ill from ethnic minority groups study their experiences mainly through interviews with patients, their relatives or staff (see eg ${ }^{1529}$ ). So as far as we know, this is the first study where specifically the mental well-being of patients from ethnic minority groups is investigated in one particular context, namely the critical care context, by means of an ethnographic research design. A study design of this kind is the most appropriate way to gain nuanced/deep insight into complex themes, for example, mental well-being of patients from ethnic minority groups in a critical care setting. Ethnographic day-by-day observations on the ward allow the study of patients' mental well-being as it is 'genuinely expressed' and from the perspective of the different people involved, from a non-prejudiced perspective.

The researcher might have had an impact on the field and the research findings as she herself has a non-Belgian ethnic background and collected data for a long period which enabled her to gain a lot of trust from patients and their families and made the latter speak to her in a very open manner. This subjectivity is a basic feature of qualitative ethnographic research. ${ }^{23} \mathrm{~A}$ weakness of this research could be the fact that the fieldwork was done in only one ICU. Therefore, transferability to other situations must be done with caution. However, by spending a lot of time 
in a variety of situations (with 10 patients and their families and all their healthcare professionals), it was possible to gain a rich insight into our sensitive research topic. There is no specific reason to believe our findings are not valuable for other similar settings. Another weakness of this study is that the researcher has only used a limited amount of ethnographic data collection techniques (in-depth interviews only with staff, negotiated interactive observation, consulting patients' medical files). This can be explained by the fact the specific ICU setting and the vulnerability of the patients and their relatives do not allow other techniques, such as video recording and full participant observation, for ethical reasons.

Our study shows that the patients included felt extremely emotionally lonely because several of their basic needs were insufficiently met. This seems to confirm previous research showing that ICU patients favour a holistic care approach and thus value attention from healthcare professionals to their biophysiological needs and to other general psychosocial and existential human needs, for example, the need for social contact, for non-medical information exchange, religious needs and participation in decision making. ${ }^{915} 1630$

Healthcare professionals' care strategies were inspired by a biomedical model of care. According to this model, healthcare professionals primarily focus on the diagnosis, treatment and cure of somatic problems, caused by biological processes and expressed in signs and symptoms. ${ }^{31}$ Care is orchestrated by healthcare professionals who try to remove patients' disease as quickly as possible by applying evidence-based medicine, although 'trial and error' can play a role. Such care strategies go often together with enforcing regulatory frameworks (eg, concerning visits) to safeguard patients' clinical condition, which is regarded as a central responsibility of healthcare professionals, a predominantly medical, unidirectional information flow interlaced with hope, little focus on psychosocial support and minimal attention to patients' communication. These care strategies perfectly align with the ICU care context, characterised by the performance of life-saving tasks, making life and death decisions, a technological orientation, a specific regulatory framework and infrastructure (eg, beds that are distant from each other, no telephone for patients), time pressure, uncertainty and professional stress. As a result, in ICUs, measurable, visual and auditable disease-related aspects are highly prioritised by staff, while less visible aspects, for example, patients' emotions, are much less acknowledged. ${ }^{79}$ On the other hand, taking into account patients' emotions becomes even more complex and challenging when patients have a different ethnocultural background. The included patients' different ethnocultural backgrounds entail specific characteristics on three interrelated levels: the patient's level (eg, religious beliefs and collectivistic orientations), the family level (eg, large and transnational family structures, specific views on care and suffering, communication forms and families' history of migration) and the level of patient-staff interaction (eg, phenotypical features, language).

Staff, occupied with urgent lifesaving care tasks, were frequently unable to react effectively to patients' verbal and non-verbal communications, often expressed by patients who completely lacked knowledge of the language of the host country. However, adequately decoding ethnoculturally diverse patients' non-verbal communication is crucial for optimal pain management and shared medical decision making. ${ }^{33}$ Furthermore, pressured healthcare professionals had little time to gain in-depth-knowledge of patients' level of skill in the language of the host society. Therefore, the staff easily developed misconceptions of patients' language proficiency based, for example, on their general knowledge of the patient's country of origin or specific phenotypical features, which led to inadequate communication or a complete absence of communication with patients about their needs. Moreover, insufficiently satisfying specific needs which were ethnoculturally inspired led to high emotional loneliness among patients. For example, a failure to meet patients' needs for multiple types of social contact (eg, proximity of others) strengthened for some patients by the collectivistic orientation of their minority cultures led to high emotional suffering among particular patients. Moreover, because relatives shared ethnocultural expectations towards patients to remain stoic and hopeful in difficult times, they did not pay enough attention to patients' specific unique basic needs, that is, their need to express desperation and participate in end of life decisions, which made patients feel left behind. In line with this finding, previous research has shown that overt communication about pain and sorrow between patients from certain ethnic minority groups and their relatives is limited. ${ }^{34}$ Additionally, relatives' high levels of hope triggered healthcare professionals, caring for patients with an uncertain prognosis, to continue life-saving treatments and reinforced their belief in their core responsibility to save patients' lives, while these patients' voices were largely unheard. Likewise, previous research demonstrates that more aggressive interventions occur at the end of the lives of patients from ethnic minority groups. ${ }^{35}$ Relatives shared high levels of hope, which were associated with an ethnocultural non-disclosure of negative information by some relatives towards other relatives, ethnoreligious beliefs ${ }^{29}$ migration-related expectations towards an unlimited field of medical possibilities in western hospitals and group pressure among the many relatives to remain hopeful.

Finally, another striking observation is that patients' mental health and the mental state of healthcare professionals working in such interethnic critical medical situations can become severely threatened due to their 
experiences of powerlessness towards meeting some of their patients' human basic needs. This can further negatively affect patients' mental state.

Our study results are certainly also of relevance to patients from majority ethnic backgrounds because we found that the ICU context and staff's biomedical approach, factors to which all patients are exposed, hindered the satisfaction of several human basic needs which are shared by all patients irrespective of their ethnocultural background. In patients from ethnic minority groups, their different ethnocultural background forms an extra important risk factor for not meeting their basic needs. Of course, the relative importance of this risk factor is different for each patient.

Mental health problems among patients, irrespective of their ethnocultural background, can primarily be reduced by investing in patient-centred care, which requires the implementation of intervention measures stimulating the coexistence of biomedical and more holistic views on health and care among staff, on the level of daily work, training and education and ICU policy/organisation. Such structural measures include staff training in mental health, flexible visiting policies, the presence of a social worker on the ward, questioning the division of labour and working hours, close cooperation with a psychologist/ psychiatrist and so on. Additionally, in a multiethnic ICU context, extra measures are urgently required, for example, cultural sensitivity training for staff and students, language facilitation and the presence of religious figures on the ward. Further (evidencebased) research is greatly needed to measure the specific impact of these recommendations in a multiethnic critical care setting.

\section{CONCLUSION}

The followed patients had specific basic needs for which they could not sufficiently turn to anybody, leaving them in a state of extreme emotional loneliness. Three interrelated risk factors for the development of mental health problems among these patients were identified: first, healthcare professionals' mainly biomedical care approach, second, the ICU work context and third, the patients' different ethnocultural background.

Contributors All authors have met the four authorship criteria as stated in the International Committee of Medical Journal Editors Recommendations for the Conduct, Reporting, Editing and Publication of Scholarly Work in Medical Journals. RLVK contributed to the research design, applied for the ethical approval, completed the data collection, contributed to the data analysis, contributed to the interpretation of the data, wrote the manuscript and is the guarantor of the manuscript. RD applied for the FWO grant, contributed to the research design, applied for the ethical approval, contributed to the data analysis, contributed to the interpretation of the data and wrote the manuscript. LH applied for the FWO grant, contributed to the research design and applied for the ethical approval, contributed to the interpretation of the data and wrote the manuscript. JB applied for the FWO grant, contributed to the research design, applied for the ethical approval, contributed to the data analysis, contributed to the interpretation of the data, wrote the manuscript and is the guarantor of the manuscript. All the authors read and approved the final manuscript.

Funding This study was funded by a research grant from the FWO (Fonds Wetenschappelijk Onderzoek-Vlaanderen, G0A3312N). The funding organisation was not involved in the design of the study, collection, analysis and interpretation of the data and in writing the manuscript.

Competing interests None declared.

Ethics approval The study (reference 2013/371) was approved by the ethics committee of the University Vrije Universiteit Brussel in December 2013.

Provenance and peer review Not commissioned; externally peer reviewed.

Data sharing statement Extra data are available by emailing RLVK.

Open Access This is an Open Access article distributed in accordance with the Creative Commons Attribution Non Commercial (CC BY-NC 4.0) license, which permits others to distribute, remix, adapt, build upon this work non-commercially, and license their derivative works on different terms, provided the original work is properly cited and the use is non-commercial. See: http://creativecommons.org/ licenses/by-nc/4.0/

(c) Article author(s) (or their employer(s) unless otherwise stated in the text of the article) 2017. All rights reserved. No commercial use is permitted unless otherwise expressly granted.

\section{REFERENCES}

1. Media centre. Mental health: strengthening our response. Geneva: World Health Organisation, 2016. http://www.who.int/mediacentre/ factsheets/fs220/en/

2. Fassaert T, De Wit MA, Tuinebreijer WC, et al. Acculturation and psychological distress among non-Western Muslim migrants-a population-based survey. Int J Soc Psychiatry 2011;57:132-43.

3. Van Keer RL, Deschepper R, Francke AL, et al. Conflicts between healthcare professionals and families of a multi-ethnic patient population during critical care: an ethnographic study. Crit Care 2015;19:441.

4. Lykkegaard K, Delmar C. Between violation and competent carelived experiences of dependency on care in the ICU. Int J Qual Stud Health Well-being 2015;10:26603.

5. Moen EK, Nåden D. Intensive care patients' perceptions of how their dignity is maintained: a phenomenological study. Intensive Crit Care Nurs 2015;31:285-93.

6. Sharma B G, Evs M, Ms K, et al. Psychological evaluation of patients in critical care/intensive care unit and patients admitted in wards. $J$ Clin Diagn Res 2014;8:WC01-WC03.

7. Price AM. Intensive care nurses' experiences of assessing and dealing with patients' psychological needs. Nurs Crit Care 2004;9:134-42.

8. Van Keer RL. Intensive suffering. Intensive Care Med 2016;42:277.

9. Alasad JA, Abu Tabar N, Ahmad MM. Patients' experience of being in intensive care units. J Crit Care 2015;30:859.e7-859.e11.

10. Karlsson V. Being conscious during mechanical ventilator treatmentpatients' and relatives 'experiences in the intensive care units. Ghotenburg: Ghotenburg University, 2012.

11. Griffin J. Forced dependency in the critically ill. Dimens Crit Care Nurs 1982;1:350-3.

12. Stayt LC, Seers K, Tutton E. Patients' experiences of technology and care in adult intensive care. J Adv Nurs 2015;71:2051-61.

13. Leman J. The dynamics of emerging ethnicities. Immigrant and indigenous ethnogenesis in confrontation: Frankfurt, Peter Lang International Academic Publishers, 2000.

14. Derluyn I, Lorant V, Dauvrin M, et al. "Naar een interculturele gezondheidszorg: Aanbevelingen van de ETHEALTH-groep voor een gelijkwaardige gezondheid en gezondheidszorg voor migranten en etnische minderheden". 2011 https://dial.uclouvain.be/pr/boreal/ object/boreal:100991

15. Garrett PW, Dickson HG, Whelan AK, et al. What do non-Englishspeaking patients value in acute care? cultural competency from the patient's perspective: a qualitative study. Ethn Health 2008;13:479-96.

16. Zeilani R, Seymour JE. Muslim women's narratives about bodily change and care during critical illness: a qualitative study. J Nurs Scholarsh 2012;44:99-107.

17. Cleveland LM. A Mexican American mother's experience in the neonatal intensive care unit. J Perinat Neonatal Nurs 2009;23:178-85. 
18. Lee SY, Weiss SJ. When East meets West: intensive care unit experiences among first-generation Chinese American parents. $J$ Nurs Scholarsh 2009;41:268-75.

19. Garrett PW, Dickson HG, Young L, et al. "The Happy Migrant Effect": perceptions of negative experiences of healthcare by patients with little or no English: a qualitative study across seven language groups. Qual Saf Health Care 2008;17:101-3.

20. Anderson KO, Green CR, Payne R. Racial and ethnic disparities in pain: causes and consequences of unequal care. J Pain 2009;10:1187-204.

21. Urden L, Stacy K, Lough M. Critical care nursing: diagnosis and management. 7th edn. St.Louis: Mosby-Elsevier, 2014.

22. Wind G. Negotiated interactive observation: doing fieldwork in hospital settings. Anthropol Med 2008;15:79-89.

23. Esterberg KG. Qualitative methods in social research. Boston: The McGraw-Hill Companies, 2002.

24. Sinuff T, Cook DJ, Giacomini M. How qualitative research can contribute to research in the intensive care unit. J Crit Care 2007;22:104-11.

25. Geertz C. The interpretation of cultures. New York: Basic Books, 1973.

26. Strauss A, Corbin J. Basics of qualitative research: grounded theory procedures and techniques. Sage: Newbury Park CA, 1990.

27. Hennink M, Hutter I, Bailey A. Qualitative research methods. London: Sage Publications, 2011.
28. Creswell JW. Qualitative inquiry \& research design. Choosing among five approaches. Lincoln: Sage Publications, 2013.

29. de Graaff FM, Francke AL, van den Muijsenbergh ME, et al. 'Palliative care': a contradiction in terms? a qualitative study of cancer patients with a Turkish or Moroccan background, their relatives and care providers. BMC Palliat Care 2010;9:19.

30. Zeilani R, Seymour JE. Muslim women's experiences of suffering in Jordanian intensive care units: a narrative study. Intensive Crit Care Nurs 2010;26:175-84.

31. Alonso Y. The biopsychosocial model in medical research: the evolution of the health concept over the last two decades. Patient Educ Couns 2004;53:239-44.

32. Riess H, Kraft-Todd G. E.M.P.A.T.H.Y.: a tool to enhance nonverbal communication between clinicians and their patients. Acad Med 2014;89:1108-12.

33. Davidhizar R, Giger JN. A review of the literature on care of clients in pain who are culturally diverse. Int Nurs Rev 2004;51:47-55.

34. de Graaff FM, Mistiaen P, Devillé WL, et al. Perspectives on care and communication involving incurably ill Turkish and Moroccan patients, relatives and professionals: a systematic literature review. BMC Palliat Care 2012;11:17.

35. Hanchate A, Kronman AC, Young-Xu Y, et al. Racial and ethnic differences in end-of-life costs: why do minorities cost more than whites? Arch Intern Med 2009;169:493-501. 